\title{
Exploring the Cultivation and Management of Graduate Students in the Public Laboratory Environment of Scientific Research Institutions
}

\author{
MA Zhi Ling ${ }^{a}$,WEI Chang Bin ${ }^{b, *}$
}

Key laboratory of Tropical fruit Biology, Ministry of Agriculture, South Subtropical Crop Research Institute, Chinese Academy of Tropical Agricultural Sciences, ZhanJiang, Guangzhou, China

$$
\text { ambelle@163.com, bwcb@163.com }
$$

${ }^{*}$ Corresponding author

Keywords: The public laboratory, Graduate student, Training, Management.

\begin{abstract}
As a basic unit of postgraduate training, the public laboratories play an important role in the management and cultivation of graduate students. This article proposes several suggestions on how to train and manage graduate students under the public laboratory environment of scientific research institutes for the management departments related postgraduate to reference.
\end{abstract}

\section{探索科研院所公共实验室环境下研究生的培养和管理}

\section{马智玲 $a$, 魏长宾 $b^{*}{ }^{*}$}

农业部热带果树生物学重点实验室, 中国热带农业科学院南亚热带作物研究所, 湛江, 广东, 中国 ambelle@163.com, bwcb@163.com

*通讯作者

关键词: 公共实验室; 研究生; 培养; 管理

中文摘要. 公共实验室作为研究生培养的基本单元, 在研究生的管理和培养方面起着举足轻 重的作用。本文针对科研院所公共实验室环境下如何进行研究生的培养和管理提出几点建议, 供研究生相关管理部门参考。

\section{1. 引言}

研究生不仅是知识的接受者, 同时也是知识创新的探索者和参与者。在当前的科研体制 下, 研究生是我国科研工作者的重要组成部分, 也是国家科技创新的生力军和后备军, 研究 生培养对科技发展意义重大。近年来, 为了适应现代社会和经济发展的需要, 我国研究生教 育改革和发展取得了很大成绩, 培养了大批优秀人才, 对我国经济建设、科技进步和社会发 展做出了巨大贡献。为了进一步满足科研探索和人才培养的需要, 越来越多的科研院所针对 科研项目建立了公共的实验室平台。

公共的实验室是研究生培养的重要场所之一，其所有的资源为研究生所共享，为研究生 科学思维和实验技能的培养提供了环境条件, 成为研究生培养的最基本组成部分。因此如何 加强和提高公共实验室环境下的研究生培养和管理也显得越来越重要, 本文就公共实验室环 境下研究生培养和管理提出几点建议, 供研究生导师及相关管理部门参考。 


\section{2. 重视公共实验室制度建设, 使研究生管理制度化、程序化和规范化。}

没有良好的管理就不能培养高水平的研究生, 为给研究生培养创造良好的实验条件, 使 研究生入室后尽快进入工作状态, 进行课题研究, 公共实验室从提高实验室管理水平出发, 建立了多项规章制度, 包括研究生准入制度、研究生自习室管理制度、实验室安全管理制度、 实验室废弃物处置制度、实验室安全事故防范与处理制度、实验室仪器使用登记和损坏赔偿 等制度。研究生首先需要参加入室前的制度培训, 讲明实验室的各项规章制度, 明确权利与 责任。

培训结束后，由实验中心统一组织考试考核，重点考察实验室安全注意事项、废弃物处 置制度、安全事故防范与处理等, 考核合格方能进入实验室。并由实验室管理人员负责指导、 检查和监督, 帮助研究生在遵守规章制度方面养成良好的习惯, 并让他们在实践中逐步体会 到每一项规章制度的遵守都是实验能否顺利进行的强有力的保证。未经过培训和考试, 不得 进入实验室开展实验工作。

\section{3. 开展实验室安全系列培训, 提高研究生的安全实验意识, 确保实验室环境及实验人员的 人身安全。}

研究生进入实验室前大多数没有经过系统的实验室安全教育, 对实验安全知识不熟悉, 安全意识淡薄。实验室安全是公共实验室建设的重中之重, 为进一步加强研究生的安全教育 与管理工作, 确保研究生的学习、生活和人身安全以及实验室安全运行, 创建平安、和谐研 究所 ${ }^{[1]}$ 。公共实验室每学期都要组织实验室安全内容的讲座及系统培训。

我们主要采用案件导入式、现场演练、观看安全记录片等方式, 再结合国内外实验室安 全突发事件和经典案例进行实验室安全教育, 帮助研究生获得必要的安全基本知识, 了解实 验室操作的规范程序以及正确应对实验室突发事件的方法, 树立安全意识, 强化组织纪律性。 其中包括邀请安保部门人员进行安全知识讲解和现场演练, 如示范灭火器使用、报警、火灾 逃生等知识; 有毒有害实验废弃物的管理与处理; 危险性物品的保存、管理以及安全使用; 遇到紧急情况时( 如漏水、有异常声音及火警等) 采取的应急措施等内容。

\section{4. 开展实验室仪器设备的使用系列培训, 帮助研究生熟悉实验室, 尽快融入科研环境。}

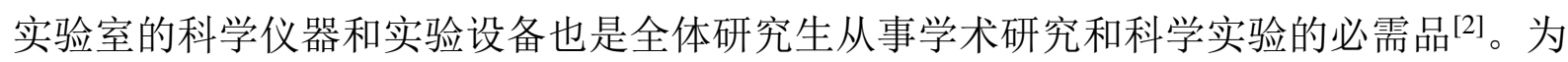
了使实验室的资源能够被充分地利用, 从而使其更有效地在研究生的培养中发挥作用。实验 中心每学期组织开展仪器设备系列培训, 帮助研究生系统熟悉和掌握基本实验技能、规范实 验操作、了解高精尖仪器设备技术, 主要包括以下几个方面的培训内容。

\section{1 实验室大型仪器设备使用培训}

贵重精密的大型仪器设备使前沿的科学研究及探索成为可能, 也有助于研究生培养质量 的提高。但是精密的仪器设备需要更精心地使用和维护, 而研究生在做实验中, 如果实验操 作方法错误或者实验操作技能不熟练, 都有可能损坏仪器设备或者减少仪器设备的使用寿命, 从而延误课题及整个实验室的工作进度 ${ }^{[3]}$ 。因此严格培训仪器设备的操作规程, 对于加强研 究生实验室管理、提高研究生培养质量就显得至关重要。

我们针对大型仪器使用的特殊性, 该类仪器的培训主要面向有需求的研究生, 大型仪器 操作资格由本人向实验中心提出申请, 实验室安排专职实验技术人员、仪器工程师等对申请 的研究生进行培训。培训多采用现场演示、网上培训和上机操作相结合的方式, 主要针对仪 器原理、操作流程、使用注意事项等内容展开, 待大型仪器使用操作培训完成后, 由实验中 心对申请人进行相关仪器的口头理论测试、实际操作能力测试。经考评合格者, 需要在实验 中心管理人员的指导下连续多次使用仪器, 最终由仪器管理人员确认申请者对仪器操作达到 
熟练程度后, 方可独立使用该仪器。获得独立操作资格证书的人员只能使用考评时指定相应 型号的仪器, 不得操作其他型号仪器设备。为提高仪器设备利用率, 获得仪器独立使用操作 资格的研究生, 可申请非工作时段进行大型仪器分析测试操作。严禁在未经培训、未获得操 作资格的情况下独立操作大型仪器设备, 以防对仪器造成损坏。

\section{2 常用仪器设备的工作原理、操作以及注意事项的培训}

学生初入实验室, 对各种仪器的使用不甚了解, 一些常用仪器设备如果使用不当, 就会 造成人的损坏。比如高速离心机、烤箱、高压灭菌锅、超净工作台、植物培养箱、 $\mathrm{pH}$ 计、 超纯水仪、各种类型离心机、酶标仪、电泳仪与PCR仪等从事科研活动常用的基本仪器设备。 此项内容主要由熟悉各仪器的科研人员主讲, 讲解仪器的应用范围、使用方法以及使用注意 事项，并通过实践操作让研究生熟知仪器的使用方法和注意事项。

\section{3 常用的实验技能培训, 确保研究生实验操作的规范性。}

由研究生所在课题的老师对本课题常用实验技能进行培训。主要培训的项目有细胞培养 技术、PCR技术、植物组织培养技术等。重点通过实践使研究生掌握基本实验技能以利于下 一步科研工作的开展。经过一段时间的培训后，新入室的研究生经考核小组进行基本实验技 能考核, 合格后方可独立进行实验。这不仅让学生尽快掌握了实验技术, 也保证了研究生实 验操作的规范性。

\section{5. 实验技术队伍建设是研究生培养的关键, 为研究生培养创造良好的软环境。}

实验室管理人员对工作是否具有积极的心态和饱满的热情将直接关系到研究生的科研能 力、创新能力的提升, 进而会影响研究生的培养质量 ${ }^{[4]}$ 。研究生科研作风和科研能力的培养 离不开高素质的实验室技术队伍, 然而实验室技术队伍建设在科研院所的重视程度不高, 技 术人员在职称评定和待遇方面均处于劣势, 导致优秀的技术人才流失, 另外公共实验室是大 型精密仪器集中的地方, 熟练掌握仪器设备的人才较少, 服务性的成分较多, 待遇不合理, 技术人才队伍难以稳定 ${ }^{[5]}$ 。实验室技术人员不但要有很强的责任心，还要有过硬的专业技术 能力和吃苦耐劳、全心全意为科研服务的精神, 了解仪器、懂操作, 还要掌握相应的实验技 术，建立实验技术平台，不断引入和开发新技术和新实验。为此，必须给予实验技术人员不 断培训、实践和学习的机会, 增强与所内外同行之间的交流, 总结经验, 不断提高自身的专 业素质和服务水平，提高实验室技术队伍的整体素质，为研究生培养创造良好的软环境 ${ }^{[6]}$ 。

本单位公共实验室目前已培养全所近20名研究生，取得了一定的效果：提高了研究生的 动手能力; 通过上机操作可以充分发挥研究生的主观能动性; 加深了对所学知识的理解, 拓 宽了知识面, 并在实验过程中发现一些现象, 及时改变测量条件, 确定所发现的现象的性质; 通过上机做实验, 研究生可以加深对仪器功能的了解, 使测量分析更具有针对性, 这样既节 省了机时, 又获得了很好的测量结果, 解决更多的科学问题。

本单位公共实验室针对研究生的培养和管理进行了一些有益的探索，两年的实践表明， 这种公共形式的培养对研究生各方面能力的提高起到了一定的积极作用, 为提高研究生的培 养质量做出了一定的贡献, 但目前仍然存在很多问题。例如如何高效地利用现有的实验仪器 设备资源; 如何进一步增强实验室综合实力以适应日益增加的研究生群体; 如何稳定实验室 技术队伍等大量的工作需要去不断探索和实践, 让公共实验室能更好地发挥其在研究生培养 中的作用。

\section{References}

[1] C. X. Ren, J. L. Han, The Role of State Key Laboratory in the Cultivation of Innovative Postgraduates, Journal of Changchun Education Institute, vol. 32, pp. 39-47, 2016. 
[2] C.W. Fan, Q Xiang ,High School Opens Experiments in Laboratory Training in Research and Development, Acta medicinae sinica, vol. 28, pp. 111-113, 2015.

[3] H. F. Huang, D. Y. Hou, X. T. Wang, Cultivating scientific-research quality of medical postgraduates based on central laboratory platform, Basic Medical Education, vol. 19, pp. 831-834, 2017.

[4] C. L. Zhang, R. Xiao, Y. C. Gao, X. J. Wang, L. L. Jiang, L. L. Niu, J. X. Wen, The exploration of laboratory's roles in the training of scientific research ability of medical postgraduates, Journal of Diseases Montrol \& Control, vol. 8, pp. 487-488, 2014.

[5] L.H. Zhang, Z.A. Shi, J.W. Wang, Y.X .Yan, Y.S. Wang, Discussion on the Training Mode of Graduate Students in the Laboratory,Cnin JLab Diagn,vol. 17, pp. 204-206, 2013.

[6] X. Yu, X. Y. Sun, Discussion on the participation of graduate students in the college open laboratory management and construction, Experiment Science and Technology, vol. 11, pp. 113-115, 2013. 